\title{
EFICIÊNCIA DE FLUENSULFONE NO CONTROLE POPULACIONAL DE M. javanica EM PIMENTA-DO-REINO APÓS TRANSPLANTE
}

\author{
Amanda Dutra de Vargas ${ }^{1}$ \\ Maria Laura Urbano Nascimento ${ }^{2}$ \\ Ualace de Oliveira dos Reis ${ }^{3}$ \\ Cíntia da Silva Alves ${ }^{4}$ \\ Guilherme de Resende Camara ${ }^{5}$ \\ Fábio Ramos Alves ${ }^{6}$
}

Resumo: Uma das doenças que mais afetam diversas culturas pelo mundo é a Meloidoginose, causada por nematoides do gênero Meloidogyne. O controle químico destaca-se como primeira opção no manejo dessa doença, embora cause riscos ao ambiente e toxicidade a organismos não alvo. Neste contexto, o estudo teve como objetivo avaliar a eficiência do Fluensulfone no controle de M. javanica na cultura de pimenta-do-reino (Piper nigrum). O experimento foi realizado no município de São Mateus - ES, onde foram testadas diferentes doses de Fluensulfone. As avaliações foram realizadas aos 120 e 180 dias após a aplicação dos tratamentos. As três maiores doses (1500 ml/ha, $2000 \mathrm{ml} / \mathrm{ha}$ e $2500 \mathrm{ml} / \mathrm{ha}$ ) apresentaram eficiência relativa acima de $80 \%$ aos 120 dias e, aos 180 dias, apenas as de $2000 \mathrm{ml} / \mathrm{ha}$ e $2500 \mathrm{ml} / \mathrm{ha}$. A dose que demonstrou maior eficácia em todo o período experimental foi a de $2500 \mathrm{ml} / \mathrm{ha}$, mostrando-se promissor o uso desta nova molécula no manejo da Meloidoginose.

Palavras-chave: Piper nigrum; Manejo; Controle Químico; Meloidoginose.

\footnotetext{
1 Universidade Federal do Espírito Santo, Brasil. E-mail: amandadvargas@hotmail.com.

2 Universidade Federal do Espírito Santo, Brasil. E-mail: urbano.marialaura@hotmail.com.

3 Universidade Federal do Espírito Santo, Brasil. E-mail: ualaceoliveira@outlook.com.

4 Faculdade de Ciências Agronômicas da Universidade Estadual Paulista "Júlio de Mesquita Filho", Brasil. Email: cintiaalvesifes@hotmail.com.

${ }^{5}$ Universidade Federal do Espírito Santo, Brasil. E-mail: grcamara@hotmail.com.

${ }^{6}$ Universidade Federal do Espírito Santo, Brasil. E-mail: fabioramosalves@yahoo.com.br.
} 